\title{
Erratum zu: Strategische Politische Kommunikation im digitalen Wandel
}

Michael Oswald und Michael Johann

\section{Erratum zu:}

\section{Oswald und M. Johann (Hrsg.), Strategische Politische Kommunikation im digitalen Wandel, https://doi.org/10.1007/978-3-658-20860-8}

Die Originalversion des Buchs wurde revidiert. Aufgrund eines Versehens wurden in acht Sätzen auf den Seiten 46, 48, 50 und 52 falsche Zahlenangaben wiedergegeben. An der grundsätzlichen Interpretation der Ergebnisse der qualitativen Inhaltsanalyse ändert sich dadurch nichts. Wir bitten den Fehler zu entschuldigen.

Die Abbildung auf Seite 47 wurde auch richtiggestellt.

Der Titel des 13. Kapitels wurde in XML auf „Back to the roots?! Der datengestützte Tür-zu-Tür-Wahlkampf in politischen Wahlkampagnen“ korrigiert. Diese Korrektur hat weder auf das gedruckte Buch noch auf das eBook eine Auswirkung, weil der Titel in den beiden Versionen des Buches richtig war.

Die korrigierten Versionen der Kapitel sind verfügbar unter https://doi.org/10.1007/978-3-658-20860-8_3

https://doi.org/10.1007/978-3-658-20860-8_13 